Louisiana State University

LSU Digital Commons

Faculty Publications

Department of Biological Sciences

6-1-1999

\title{
Phytochelatin synthase genes from Arabidopsis and the yeast Schizosaccharomyces pombe
}

\author{
Suk Bong $\mathrm{Ha}$ \\ University of Melbourne \\ Aaron P. Smith \\ Purdue University \\ Ross Howden \\ University of Melbourne \\ Wendy M. Dietrich \\ University of Melbourne \\ Sarah Bugg \\ Peter Maccallum Cancer Centre
}

See next page for additional authors

Follow this and additional works at: https://digitalcommons.Isu.edu/biosci_pubs

\section{Recommended Citation}

Ha, S., Smith, A., Howden, R., Dietrich, W., Bugg, S., O'Connell, M., Goldsbrough, P., \& Cobbett, C. (1999). Phytochelatin synthase genes from Arabidopsis and the yeast Schizosaccharomyces pombe. Plant Cell, 11 (6), 1153-1163. https://doi.org/10.1105/tpc.11.6.1153

This Article is brought to you for free and open access by the Department of Biological Sciences at LSU Digital Commons. It has been accepted for inclusion in Faculty Publications by an authorized administrator of LSU Digital Commons. For more information, please contact ir@lsu.edu. 


\section{Authors}

Suk Bong Ha, Aaron P. Smith, Ross Howden, Wendy M. Dietrich, Sarah Bugg, Matthew J. O'Connell, Peter B. Goldsbrough, and Christopher S. Cobbett 


\title{
Phytochelatin Synthase Genes from Arabidopsis and the Yeast Schizosaccharomyces pombe
}

\author{
Suk-Bong Ha, a Aaron P. Smith, ${ }^{b}$ Ross Howden, ${ }^{a}$ Wendy M. Dietrich, ${ }^{a}$ Sarah Bugg, ${ }^{c}$ Matthew J . O'C onnell, a,c \\ Peter B. Goldsbrough, ${ }^{b}$ and C hristopher S. Cobbett ${ }^{a, 1}$ \\ a Department of Genetics, University of Melbourne, Parkville, Victoria 3052, Australia \\ b Department of Horticulture and Landscape Architecture, Purdue University, West Lafayette, Indiana 47907-1165 \\ c Trescowthick Research Laboratories, Peter MacCallum Cancer Institute, Melbourne, Victoria 3000, Australia
}

\begin{abstract}
Phytochelatins (PCs), a family of heavy metal-inducible peptides important in the detoxification of heavy metals, have been identified in plants and some microorganisms, including Schizosaccharomyces pombe, but not in animals. PCs are synthesized enzymatically from glutathione (GSH) by PC synthase in the presence of heavy metal ions. In Arabidopsis, the CAD1 gene, identified by using Cd-sensitive, PC-deficient cad1 mutants, has been proposed to encode PC synthase. Using a positional cloning strategy, we have isolated the CAD1 gene. Database searches identified a homologous gene in S. pombe, and a mutant with a targeted deletion of this gene was also Cd sensitive and PC deficient. Extracts of Escherichia coli cells expressing a CAD1 cDNA or the S. pombe gene catalyzing GSH-dependent, heavy metal-activated synthesis of PCs in vitro demonstrated that both genes encode PC synthase activity. Both enzymes were activated by a range of metal ions. In contrast, reverse transcription-polymerase chain reaction experiments showed that expression of the CAD1 mRNA is not influenced by the presence of Cd. A comparison of the two predicted amino acid sequences revealed a highly conserved $\mathrm{N}$-terminal region, which is presumed to be the catalytic domain, and a variable $\mathrm{C}$-terminal region containing multiple $\mathrm{Cys}$ residues, which is proposed to be involved in activation of the enzyme by metal ions. Interestingly, a similar gene was identified in the nematode, Caenorhabditis elegans, suggesting that PCs may also be expressed in some animal species.
\end{abstract}

\section{INTRODUCTION}

Plants, like other organisms, have adaptive mechanisms whereby they are able to respond to both nutrient deficiencies and toxicities. One response of plants to heavy metal stress is the induction of phytochelatins (PCs), a family of related peptides that have the structure $(\gamma \text {-Glu-Cys })_{n}-$ Gly (where $n>1$ ) and are clearly related to the tripeptide glutathione (GSH), for which $n=1$. These peptides have been referred to variously as cadystins (from Schizosaccharomyces pombe), poly- $(\gamma-E C)_{n} G$ peptides, $C d$ binding peptides, and PCs. They are broadly classified as class III metallothioneins and are enzymatically synthesized, unlike the gene-encoded class I and II metallothioneins (Kägi, 1991). PCs have been identified in a wide variety of plant species, including monocots, dicots, gymnosperms, and algae (Gekeler et al., 1989), in addition to various fungal species (Mehra et al., 1988; Kneer et al., 1992) and marine diatoms (Morelli and Pratesi, 1997), but not in any animal species. PC synthesis is rapidly

\footnotetext{
${ }^{1}$ To whom correspondence should be addressed. E-mail c.cobbett @genetics.unimelb.edu.au; fax 613-93445139.
}

induced in the presence of a wide range of heavy metals (Grill et al., 1987; Maitani et al., 1996). However, low levels of PCs can be detected in plant tissues or cultures of yeast or plant cells grown in medium containing trace levels of essential heavy metals (G rill et al., 1988; Kneer and Zenk, 1992; Howden et al., 1995a).

Various studies have confirmed that PCs are synthesized from GSH. For example, exposure of whole plants or plant cell cultures to an inhibitor of GSH biosynthesis, namely, buthionine sulfoximine, also inhibited the induction of PCS and/or conferred hypersensitivity to $\mathrm{Cd}$ (Steffens et al., 1986; Reese and Wagner, 1987; Scheller et al., 1987; Howden and Cobbett, 1992). In addition, mutants of both S. pombe and Arabidopsis having defects in genes encoding GSH biosynthetic enzymes are deficient in PCs and hypersensitive to some metal ions (Mutoh and Hayashi, 1988; Glaeser et al., 1991; Howden et al., 1995b).

The role of GSH as a substrate for PC biosynthesis was confirmed with the identification of an enzyme activity from cultured cells of Silene cucubalis that synthesized PCs from GSH in vitro (Grill et al., 1989). The reaction involved the transpeptidation of the $\gamma$-Glu-Cys moiety of GSH onto, 
initially, a second GSH molecule to form $P C_{(n=2)}$ or, in later stages of the incubation, onto a PC molecule to produce an $(n+1)$ oligomer. This $\gamma$-Glu-Cys dipeptidyl transpeptidase (EC 2.3.2.15) has been named PC synthase. The partially purified enzyme was active only in the presence of metal ions. A range of metal ions, all of which were known to induce $P C$ synthesis in plants in vivo, were effective activators of the enzyme in vitro. In these reactions, PC biosynthesis continued until the activating metal ions were chelated either by the PCs formed or by the addition of a metal chelator, such as EDTA (Loeffler et al., 1989). Chelation by PCs provides a mechanism to autoregulate the biosynthesis of PCs in which the product of the reaction chelates the activating metal, thereby terminating the reaction. Similar PC synthase activities have been detected in pea (Klapheck et al., 1995), tomato (Chen et al., 1997), and Arabidopsis (Howden et al., 1995a). PC synthase activity is expressed constitutively in a number of species examined (G rill et al., 1989; Klapheck et al., 1995; Chen et al., 1997).

In addition to GSH and PC biosynthetic activities, a number of other processes important in the function of PCs in vivo have been identified. In both plants and S. pombe, PC$\mathrm{Cd}$ complexes are sequestered to the vacuole. In extracts of S. pombe and, in some cases, plants (Reese et al., 1992; Speiser et al., 1992a; Howden et al., 1995a) exposed to Cd, high and low molecular weight PC-Cd complexes can be resolved by using gel filtration chromatography. A Cd-sensitive mutant of S. pombe, $\mathrm{hmt1}^{-}$, which is unable to form high molecular weight complexes, facilitated identification of a gene encoding a member of the family of ATP binding cassette membrane transport proteins. The HMT1 gene product is located in the vacuolar membrane and is responsible for the transport of PCs and PC-Cd complexes into the vacuole (Ortiz et al., 1992, 1995). High molecular weight complexes also contain acid-labile sulfide, which increases both the amount of $\mathrm{Cd}$ in a complex and the stability of the complex (Reese and Winge, 1988; Dameron et al., 1989; Mehra et al., 1994). Other Cd-sensitive mutants of S. pombe have allowed identification of genes that are required for the production of high molecular weight PC-Cd complexes. These gene products are proposed to be involved in the biosynthesis of sulfur-containing compounds, which lead to incorporation of sulfide into high molecular weight complexes (Speiser et al., 1992b; J uang et al., 1993).

The isolation and characterization of $\mathrm{Cd}$-sensitive mutants of Arabidopsis have helped to identify two loci involved in PC biosynthesis. The cad2-1 mutant is partially deficient in $\gamma$-Glu-Cys synthetase activity, which is the first of two enzymes in the GSH biosynthetic pathway, and the cad2-1 mutation lies in the structural gene encoding $\gamma$-Glu-Cys synthetase (Cobbett et al., 1998). In contrast, cad 1 mutants retained wild-type levels of GSH and were deficient in PC biosynthesis in vivo and $P C$ synthase activity in vitro (Howden et al., 1995a). Thus, the CAD1 gene was predicted to encode PC synthase. Here, we describe the isolation of the CAD1 gene by using a positional cloning strategy and demonstrate that both CAD1 and a homologous gene in S. pombe encode PC synthase activity.

\section{RESULTS}

\section{Positional Cloning of the CAD1 Gene}

CAD1 is closely linked to TRANSPARENT TESTA3 (TT3) on chromosome 5 (Howden and Cobbett, 1992). Two restriction fragment length polymorphism (RFLP) markers, m423 and sAt2105 (CRA1), flanking TT3 and the clone pAt5-91.5, which corresponds to TT3, were used to continue mapping the position of CAD1 by using progeny of a cross between the cad1-1 mutant (Columbia ecotype) and the Landsberg erecta ecotype. The relative order of these markers and the calculated genetic distances from CAD1 are shown in Figure 1. Two recombination events between pAt5-91.5 and CAD1 were observed in $91 \mathrm{~F}_{3}$ families scored, whereas no recombinants between CAD1 and SAt2105 (CRA1) were identified in $63 \mathrm{~F}_{3}$ families. To position CAD1 more closely with respect to molecular markers in the region, we isolated 26 recombinants between TT3 and CAD1. Additional molecular markers shown in Figure 1 were used to position the 26 recombination events. These included markers corresponding to regions of a genomic clone, MRH10, which had been sequenced as part of the Arabidopsis Genome Initiative.

The rightmost six recombination events occurred between markers corresponding to genes MRH10.7 and MRH10.11, and the recombination points were further mapped using additional markers from this interval (Figure 1). This analysis demonstrated that CAD1 lay to the right of a marker in the vicinity of base pair position 60,000 of the MRH10 sequence. Two predicted genes, $\mathrm{MRH} 10.11$ and $\mathrm{MRH} 10.12$, lay on $\mathrm{MRH} 10$ to the right of this marker. The latter is predicted to encode a transcription factor, whereas the former is of unknown function. To investigate the possibility that MRH10.11 is the CAD1 gene, we determined the nucleotide sequence of MRH10.11 in each of four cad1 mutants. In each case, a different single base pair substitution was identified, indicating that MRH10.11 is the CAD1 gene. The cad1-1, cad1-4, and cad1-5 mutations were base pair transitions generated by ethyl methanesulfonate, whereas the cad1-3 mutation was a G-Cto-C-G transversion generated by 1,2:3,4-diepoxybutane.

To confirm that MRH10.11 is CAD1, we ligated a genomic fragment spanning the gene into the binary vector pBI101.3 and transformed it into the cad1-3 mutant. The progeny of two kanamycin-resistant transgenic lines were examined in detail. Each line segregated kanamycin-resistant and kanamycin-sensitive and $\mathrm{Cd}$-resistant (wild-type) and $\mathrm{Cd}$-sensitive individuals. Kanamycin-resistant seed lings were uniformly $\mathrm{Cd}$ resistant, demonstrating that the transgene complemented the phenotype of the cad1-3 mutant (data not shown). The progeny of two transgenic lines of the cad1-3 mutant transformed with pBI101.3 alone were uniformly $\mathrm{Cd}$ sensitive. 
A

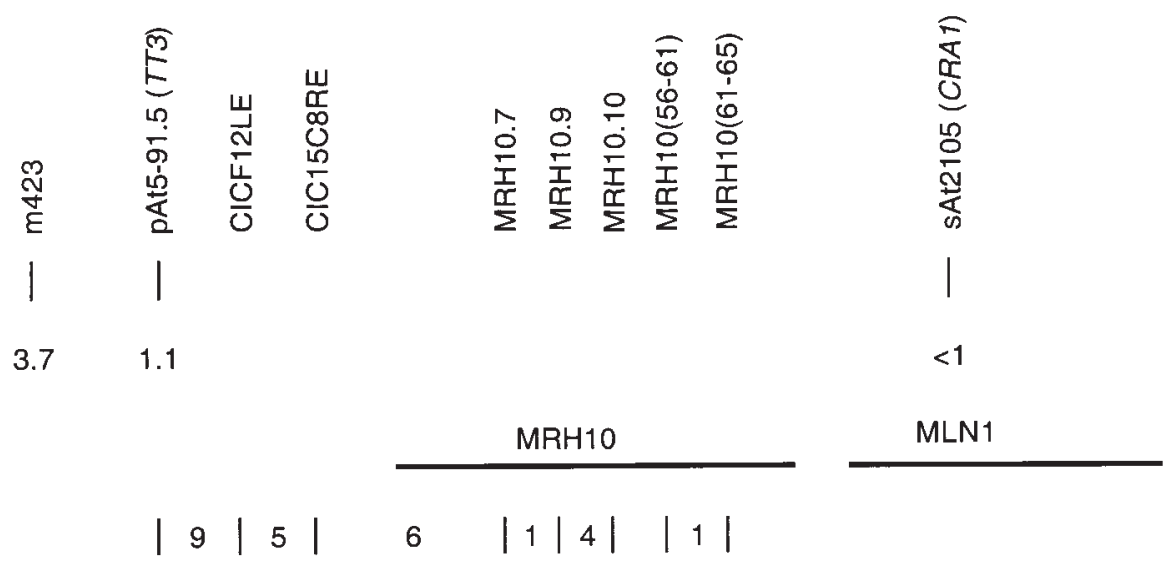

E

$$
\begin{aligned}
& \text { MRH10.11 } \\
& =C A D 1
\end{aligned}
$$

Figure 1. Mapping CAD1 with Respect to Molecular Markers.

(A) RFLP and PCR-amplified polymorphic markers. Many of these correspond to regions of the genomic clone MRH10 (GenBank accession number AB006703) (not to scale).

(B) Map distances (in centimorgans) between the CAD1 and RFLP markers indicated.

(C) Genomic clones MRH10 and MLN1 aligned with the markers shown in (A).

(D) Positions of 26 recombination events in the TT3-CAD1 interval mapped with respect to the markers shown in (A).

(E) Position of the CAD1 (MRH10.11) gene.

\section{Characteristics of CAD1 and Homologous Genes from Other Organisms}

A genomic polymerase chain reaction ( $P C R$ ) fragment corresponding to $\mathrm{MRH} 10.11$ was used as a probe to identify a cDNA clone containing a 1.6-kb insert. A comparison of the nucleotide sequence of this CDNA with the genomic sequence of MRH10.11 showed the intron/exon structure illustrated in Figure 2A. This structure is different from that predicted in the Arabidopsis Genome Initiative database due to the misidentification of the 5' splice site of the first intron and the consequent inclusion of an additional $5^{\prime}$ exon to complete an open reading frame. This predicted exon is not present in the CDNA, and reverse transcription-PCR (RT-PCR) experiments using a primer corresponding to part of this exon failed to generate a product (data not shown), suggesting that this region is not present in the mature mRNA. The cDNA contains an open reading frame that would encode a 55-kD protein of 485 amino acids. Database searches identified genes encoding similar proteins in S. pombe and the nematode Caenorhabditis elegans. An alignment of the deduced amino acid sequences of these gene products is shown in Figure $2 \mathrm{~B}$. The $\mathrm{N}$-terminal region of each is well conserved. A pairwise comparison of the region corresponding to the first 220 amino acids of the Arabidopsis sequence showed 40 to $50 \%$ identity. Of these, 71 residues are identical across the three gene products. In contrast, the C-terminal region shows no apparent sequence conservation. The only identifiable common feature of the C-terminal region is the occurrence of multiple Cys residues. The plant, yeast, and nematode gene products have 10,7 , and 10 Cys residues, respectively, in the C-terminal region, including two, three, and two adjacent pairs, respectively. However, there is no apparent conservation of the positions of these Cys residues relative to each other.

The effects of the mutations identified in the four cad 1 mutant alleles are also shown in Figure 2B. The cad1-1 and cad1-3 mutations change residues conserved across the three sequences. The cad1-4 mutation alters a residue that is not conserved but is immediately adjacent to a highly conserved block of sequence. The cad1-5 mutation would result in premature termination of translation. The truncated product would contain the conserved $\mathrm{N}$-terminal domain but would lack the greater part of the $\mathrm{C}$-terminal domain, including nine of the $10 \mathrm{Cys}$ residues.

\section{Characterization of a PC-Deficient Mutant of S. pombe}

S. pombe has also been used as a model organism for the genetic analysis of PC biosynthesis and function. Because the Arabidopsis cad1 mutants have a $\mathrm{Cd}$-sensitive phenotype, 
A

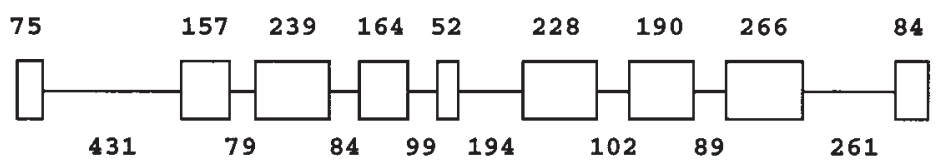

B

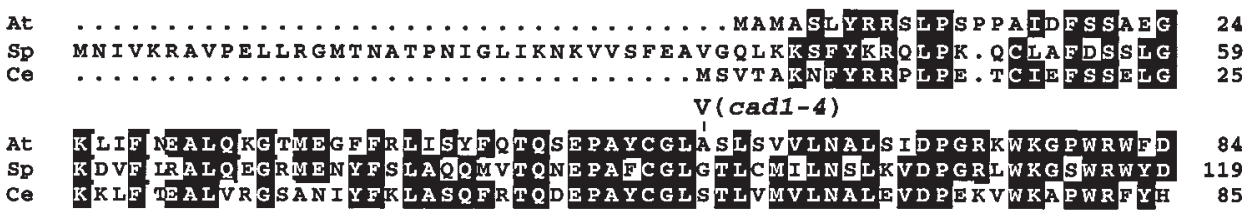

C KKLF TELVRGSANIYFKLASOFRTODEPAYCGLSTIVMVLNALEVDPEKVWKAPVRFYH $Y(\operatorname{cad} 1-1)$

At ESMLDCCEPLEVVKEKGISFGKVVCIAHCSGAK. VEAFRTSQSTIDDFRKFVVKCTSSE 142 SP QYMLDCCRSLSDIEKDGVTLEEFSCLA CNGLRTITKCVKDVS. . FDEFRKDVISCSTIE 177 Ce ESMLDCCVPLENIRKSGINLQRESCIAKCNRLKSTVISGDNSPDFLKKFRTSIVNSVRSD 145 $C(\operatorname{cad} 1-3)$

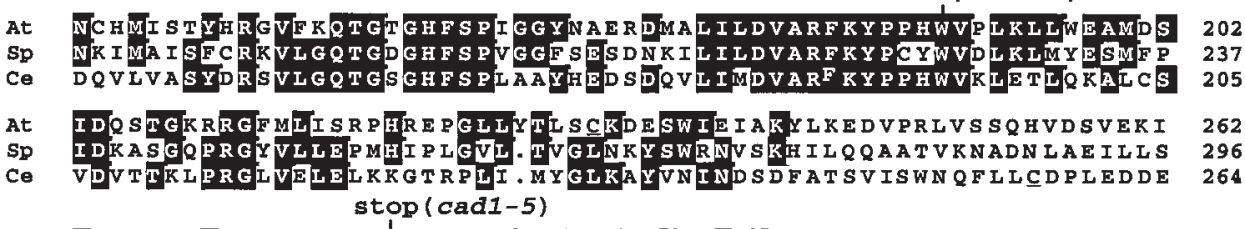

At ISVVFRSIPSNFNOFIRWVAETRITEDSNONLSAEEKSRLKLKOLVLKEVHETELFKHIN 322 SP INQSSIPLIQERSNSSKSGDFEHFKGCIRSTKTHLFLKHTNTNVEYITMAFWAIFSIPM 356 Ce EERLCCRRFGQCFAPHAMCCTQKRFDADQKNSCTECSTDQNEACKMICSEIRRTRFAE 324 At KFLSTVGYEDSTYAAAKACCQGAEILGSPSKEFCCRETCVKCIKGPDDSEGTVVTGVV 382 Sp IQKALPKGVLEEIQSLLKEVEISEINTQLTALKKQLDSLTHCCKTDTGCCSSSCCKNT

Ce FSSSAVAALLIAW PFEKGYSERSDRIGNLAEKYKNEFSAETMNEMSE

At VRDGNEQKVDLLVPSTTECECGPEATYPAGNDVFTALLLALPROTWSGIKDQALMHEMK

At QLISMASLPTLLQEEVLHLRRQLQLLKRCQENKEEDDLAAPAY

Figure 2. Structure and Sequence of CAD1.

(A) The exon/intron structure of CAD1. Lengths of exons (above) and introns (below) are in base pairs. The ends of the schematic correspond to the ends of the CDNA sequence.

(B) Amino acid sequences were derived from nucleotide sequences of the Arabidopsis (At) CAD1 CDNA (GenBank accession number AF135155), the S. pombe (Sp) gene SPAC3H1.10 (GenBank accession number Z68144), and the C. elegans (Ce) gene F54D5.1 (GenBank accession number Z66513). Dots have been inserted to maximize alignment. Residues identical in two or more of the sequences are highlighted. In the C-terminal regions, Cys residues are underlined. The amino acid changes in the cad1 mutant alleles are indicated above the Arabidopsis sequence.

a similar phenotype would be expected for the analogous $\mathrm{S}$. pombe mutant. To test this hypothesis, we constructed a targeted deletion of the $\mathrm{S}$. pombe gene and tested the mutant derivative for growth in the presence of $\mathrm{Cd}$. Figure $3 \mathrm{~A}$ shows that the mutant is $C d$ sensitive. Whereas the wildtype strain showed inhibition of growth only on medium containing $300 \mu \mathrm{M} \mathrm{CdSO}_{4}$, the mutant derivative was inhibited by concentrations of $\mathrm{CdSO}_{4}$ as low as $30 \mu \mathrm{M}$. The mutant was also more sensitive than the wild type to $\mathrm{AsO}_{4}{ }^{2-}$ (Figure $3 \mathrm{~A}$ ) but not to $\mathrm{Cu}$ (Figure $3 \mathrm{~A}$ ), $\mathrm{Zn}, \mathrm{Hg}, \mathrm{SeO}_{3}{ }^{2-}, \mathrm{Ag}$, or $\mathrm{Ni}$ ions (data not shown). Furthermore, because cadl mutants of Arabidopsis are PC deficient, the S. pombe mutant was tested for $P C$ induction in the presence of $C d$. Figure $3 \mathrm{~B}$ shows the mutant was deficient in $\mathrm{PCs}(<2 \mathrm{nmol}$ of $\gamma$-Glu-Cys equivalents per mg of protein) compared with the wild-type strain $(153 \pm 4 \mathrm{nmol} \gamma$-Glu-Cys equivalents per mg of protein). This demonstrates that the function of these genes in the two organisms is analogous.

To further compare the involvement of PCs in the detoxification of different heavy metals in S. pombe and Arabidopsis, we tested the cad1-3 mutant, which lacks detectable $P C s$, for sensitivity to a similar range of heavy metal ions. The relative concentrations of metal ion in the medium, which resulted in equivalent inhibition of growth of cad1-3 and wild-type seedlings, allowed a semiquantitative measurement of the degree of sensitivity of the mutant. Figure 4, for example, shows the data obtained for $\mathrm{AsO}_{4}{ }^{2-}, \mathrm{Hg}$, and $\mathrm{Ni}$. The mutant is $\sim 10$ - to 20 -fold more sensitive than is the wild type to $\mathrm{AsO}_{4}{ }^{2-}$ and approximately twofold more sensitive to $\mathrm{Hg}$; no difference between mutant and wild type was observed in the presence of $\mathrm{Ni}$. Like the $\mathrm{S}$. pombe mutant, cad1-3 was highly sensitive to $\mathrm{Cd}$ (20- to 40-fold) and 
$\mathrm{AsO}_{4}{ }^{2-}$ and no more sensitive than was the wild type (less than twofold) to $\mathrm{Zn}, \mathrm{SeO}_{3}{ }^{2-}$, and $\mathrm{Ni}$ ions. In contrast to the S. pombe mutant, cad1-3 was slightly sensitive to $\mathrm{Cu}$ (twofold) and $\mathrm{Hg}$ (twofold) and showed intermediate sensitivity to $\mathrm{Ag}$ (approximately eightfold) ions.

A

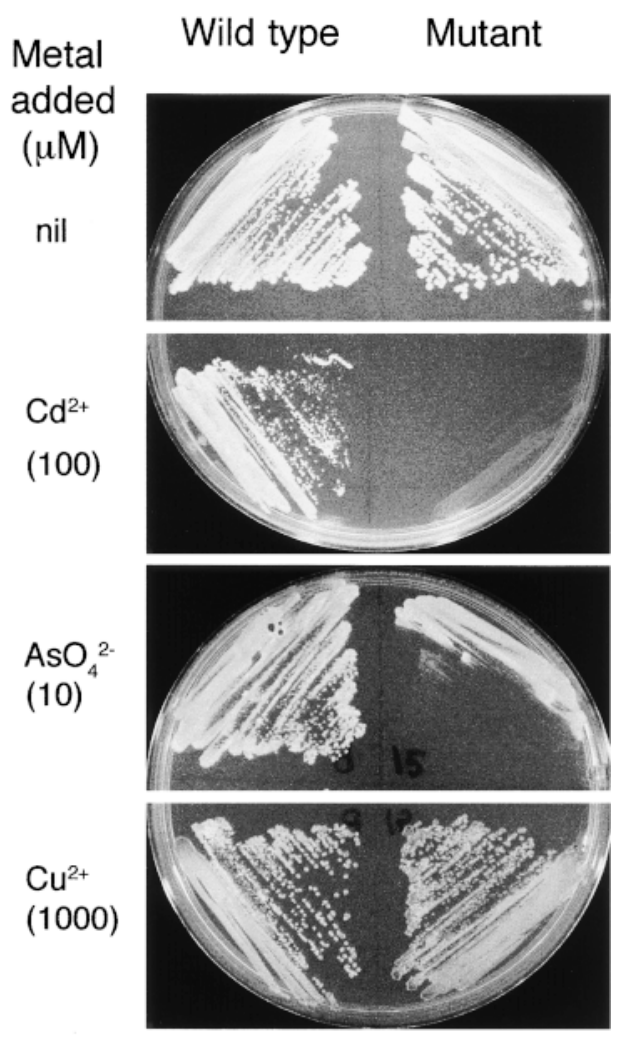

B

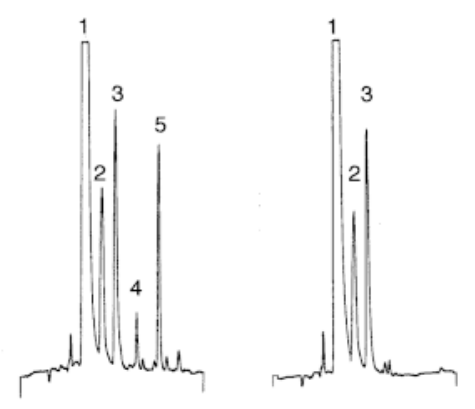

Figure 3. Heavy Metal Sensitivity of an S. pombe PC-Deficient Mutant.

(A) Mutant and wild-type strains were grown on medium containing the added heavy metal ions, as indicated. nil; no added metal ions.

(B) Mutant and wild-type strains were assayed by HPLC for PC accumulation. Peaks are identified as follows: peak $1, \beta$-mercaptoethanol; peak 2, GSH; peak 3, standard; peak 4, $\mathrm{PC}_{(\mathrm{n}=2)}$; and peak $5, \mathrm{PC}_{(\mathrm{n}=3)}$.

\section{Expression of PC Synthase Activity in Escherichia coli}

To confirm that both the S. pombe and Arabidopsis genes encode PC synthase activity, we expressed the proteins encoded by the predicted open reading frames of these genes in $\mathrm{E}$. coli. The open reading frames were ligated into the expression vector $\mathrm{pTrc} 99 \mathrm{~A}$, in which translation initiating at the predicted $M$ et residues shown in Figure $2 B$ is driven from a bacterial Shine-Delgarno sequence. Protein extracts prepared from bacteria transformed with these constructs were able to catalyze the synthesis of $\mathrm{PC}_{(\mathrm{n}=2 \text { to } 4)}$ in vitro. No activity $(<0.1 \mathrm{nmol} \gamma$-Glu-Cys transferred per min per mg of protein) was detected in the absence of GSH or if the extract were boiled or in extracts of cells containing pTrc99A alone. B oth the expressed plant and yeast enzymes were activated to variable extents by a range of metal ions known to induce PC synthesis in vivo in plants and S. pombe (Table 1). PC synthase activity in extracts from $\mathrm{E}$. coli cells expressing CAD1 was up to 40 -fold higher than that observed in extracts from cells expressing the $\mathrm{S}$. pombe gene.

\section{Expression of the CAD1 Gene}

A number of previous studies have shown that PC synthase activity is expressed constitutively in plant tissues or cell cultures (G rill et al., 1989; Klapheck et al., 1995; Chen et al., 1997). To examine the expression of the CAD1 gene in response to exposure to $C d$, we isolated total RNA from roots and leaves of plants grown in the presence or absence of $\mathrm{Cd}$. RT-PCR was used to generate CDNA and amplification products using primers specific for CAD1 and, as a control, primers corresponding to absolutely conserved regions of all the known actin cDNAs in Arabidopsis. Each primer pair flanked an intron, allowing products amplified from cDNAs to be distinguished from those arising from genomic DNA contamination. Preliminary experiments demonstrated that both the number of PCR cycles and the amount of CDNA template used limited the amount of product obtained (data not shown). The results are shown in Figure 5. Only a single fragment corresponding to the predicted CDNA product was observed for each primer pair. Similar amounts of actinspecific product were obtained for all samples. A greater amount of CAD1-specific product was obtained with root compared with leaf cDNA. No differences were observed between samples from tissues exposed or not exposed to $\mathrm{Cd}$, indicating that expression of the gene is not induced in the presence of $\mathrm{Cd}$.

\section{Sequences Homologous to CAD1 in Arabidopsis}

The absence of any detectable PC expression in the cad 1-3 mutant in the presence of $\mathrm{C} d$ suggested that the Columbia ecotype has only a single gene expressing this function. However, a search of the Arabidopsis Genome Initiative database 


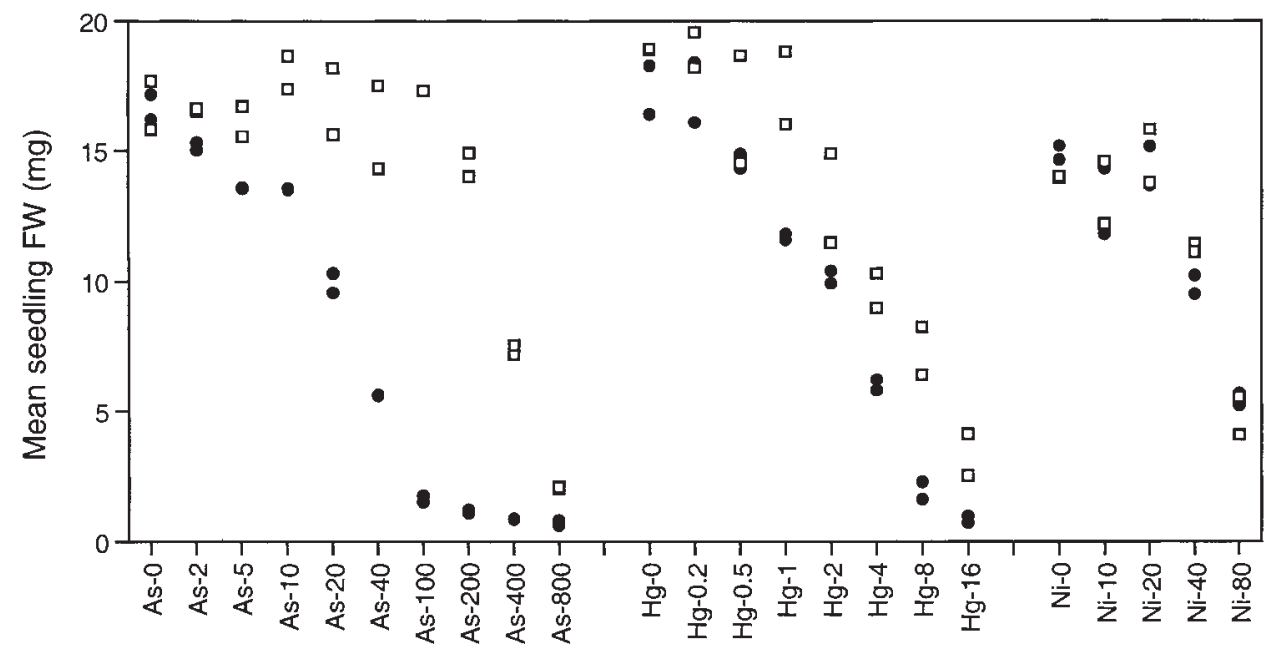

Figure 4. Sensitivity of the cad1-3 Mutant to Different Heavy Metals.

Fresh weight (FW) of wild-type (open squares) and cad1-3 (filled circles) plants was measured after growth in the presence of $\mathrm{NaAsO}_{4}(\mathrm{As})$, $\mathrm{HgSO}_{4}(\mathrm{Hg})$, or $\mathrm{NiCl}_{2}(\mathrm{Ni})$ at various concentrations (given in micromoles per liter). Note that the $\mathrm{x}$ axis is not to scale. Each data point represents the mean fresh weight of 10 plants. Standard errors are not shown for clarity. The largest standard error calculated for any data set was 1.6 mg.

indicates that there are at least two additional sequences in the Arabidopsis genome that are related to CAD1. The first is a 360 -bp region of the $1.1-\mathrm{kb}$ intergenic region between CAD1 (MRH10.11) and MRH10.12. This region is similar to portions of exons 7 and 8 of CAD1 (data not shown). This sequence does not appear to contain an intact gene and may have arisen from the duplication of part or all of CAD1.

The second region of similarity is a predicted gene on clone F21M11 from chromosome 1 (GenBank accession number AC003027), which is similar in both sequence and apparent structure to CAD1. The positions of the predicted introns of this second gene are identical to those of CAD1. However, the sizes and sequences of the introns vary considerably between the two genes, suggesting that one is not a recent duplication of the other. Predicted exons differ in size by at most a single codon, with the exception of an apparent 90-bp deletion within exon 8 of the CAD1 homolog, that would result, compared with CAD1, in an in-frame deletion of part of the $\mathrm{C}$-terminal variable domain of the predicted gene product. The deduced amino acid sequence for the CAD1 homolog is $84 \%$ identical to CAD1.

\section{DISCUSSION}

The previous demonstration that cad 1 mutants had normal levels of GSH, were PC deficient, and lacked detectable PC synthase activity in vitro led to the prediction that the CAD1 gene encodes the PC synthase activity (Howden et al., 1995a). Using a positional cloning strategy, we have demon- strated that the gene MRH10.11, predicted from the Arabidopsis Genome Initiative genomic sequence, is CAD1. In support of this conclusion, we demonstrated that four independent cad 1 mutants have base pair substitutions in the MRH10.11 gene and that the wild-type gene can complement the cadl $\mathrm{Cd}$-sensitive phenotype. To confirm that CAD1 encodes PC synthase activity, we expressed the CAD1 cDNA in E. coli. Previous studies on plant PC synthase activities have shown that PC synthesis is dependent on GSH as a substrate and is activated by various heavy metal ions (Grill et al., 1989; Klapheck et al., 1995; Chen et al., 1997). Consistent with these observations, GSH-dependent, heavy metal-activated synthesis of PCs was catalyzed by extracts of $E$. coli cells expressing the CAD1 gene product. A similar range of metal ions activated the enzyme with variable efficiency.

In addition to Arabidopsis, S. pombe has been used as a model organism for the genetic analysis of PC biosynthesis and function. Whereas a number of genes influencing the formation of PC-Cd complexes have been identified by screening for Cd-sensitive mutants (Ortiz et al., 1992; Speiser et al., 1992b), the gene encoding PC synthase has not been isolated using this approach. A homolog of the CAD1 gene was identified in S. pombe; to strengthen the conclusion that this family of genes encodes PC synthase, we have included here studies of the S. pombe gene. As for cad 1 mutants of Arabidopsis, the corresponding S. pombe mutant was heavy metal sensitive and PC deficent. Hayashi et al. (1991) proposed that there are two pathways for PC biosynthesis in S. pombe. In addition to the pathway found in plants (transfer of $\gamma$-Glu-Cys from GSH to an acceptor), 
they present evidence for a pathway in which $\gamma$-Glu-Cys is polymerized and then a terminal Gly is added by GSH synthetase. However, because mutation of the $\mathrm{S}$. pombe homolog of CAD1 effectively abolishes PC expression, it is unlikely that such a pathway is of any physiological significance. Interestingly, whereas PCs have been reported in Saccharomyces cerevisiae (Kneer et al., 1992), there is no gene in the S. cerevisiae genome with similarity to CAD1 or the $S$. pombe homolog. This may indicate that PCS can, in some organisms, be synthesized via an alternative pathway.

GSH-dependent, metal-activated PC synthesis was also detected in extracts of $E$. coli expressing the $S$. pombe gene. Activity in extracts from cells expressing the CAD1 cDNA was up to 40 -fold higher than that observed with the S. pombe expression construct. This may be due to differences in the level of expression or stability of the enzymes in E. coli, possibly resulting from differential mRNA stability, translational efficiency influenced by codon usage, or inappropriate protein folding. Alternatively, it may simply reflect the intrinsic activity of the different gene products under the assay conditions used. In addition, whereas a wide range in the efficiency of activation of the expressed plant enzyme by different heavy metals-for example, a 50-fold difference for $\mathrm{Ag}^{+}$compared with $\mathrm{Pb}^{2+}$-was observed, considerably smaller differences in activation of the expressed yeast enzyme by the same metal ions were detected. However, in view of the uncertainty of the structure and stability of the expressed polypeptides, further investigation is required to characterize the apparent differences between these activities.

The degree of sensitivity of the PC-deficient mutants to specific heavy metals gives an indication of the role of PCs in detoxification of these metals in vivo. A comparison of the relative sensitivity of the Arabidopsis and S. pombe mutants to different heavy metals revealed a similar but not identical pattern. In both organisms, PCs appeared to play an important role in $\mathrm{Cd}$ and arsenate detoxification but had no appar-

Table 1. Expression of PC Synthase Activity in E. coli

\begin{tabular}{lll}
\hline & \multicolumn{2}{l}{$\begin{array}{l}\text { PC Synthase Activity } \pm \text { SEa } \\
\text { (nmol } \gamma \text {-Glu-Cys Transferred } \mathrm{min}^{-1} \mathrm{mg}^{-1} \text { Protein) }\end{array}$} \\
\cline { 2 - 3 } Metal Ion $(\mu \mathrm{M})$ & Arabidopsis & S. pombe \\
\hline None & $<0.1(<0.1)$ & $0.3 \pm 0.2(5)$ \\
$\mathrm{Cd}^{2+}(100)$ & $116 \pm 30(100)$ & $6.5 \pm 0.1(100)$ \\
$\mathrm{Cu}^{2+}(50)$ & $253 \pm 2(218)$ & $4.6 \pm 0.1(71)$ \\
$\mathrm{Ag}^{+}(100)$ & $230 \pm 17(198)$ & $3.6 \pm 0.5(55)$ \\
$\mathrm{Hg}^{2+}(50)$ & $97 \pm 20(84)$ & $2.8 \pm 0.4(43)$ \\
$\mathrm{Zn}^{2+}(100)$ & $9.7 \pm 2.3(8)$ & $3.7 \pm 0.4(57)$ \\
$\mathrm{Pb}^{2+}(100)$ & $4.7 \pm 0.8(4)$ & $4.2 \pm 0.5(65)$ \\
\hline
\end{tabular}

a The Arabidopsis CDNA and S. pombe gene encoding PC synthase were expressed in E. coli, and the extracts were assayed $(n=3)$ for $P C$ synthase activity in the presence of heavy metal ions. The percentage of activity relative to that in the presence of $\mathrm{Cd}^{2+}$ is shown within parentheses.

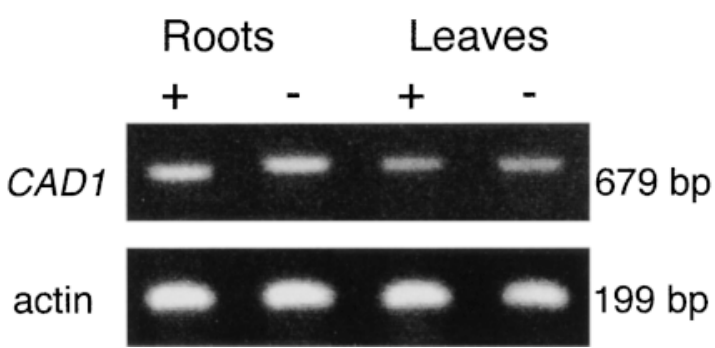

Figure 5. Expression of CAD1.

RT-PCRs were conducted using total RNA extracted from wild-type leaf and root tissue of plants exposed (+) or not exposed (-) to 1.5 $\mu \mathrm{M} \mathrm{CdSO}_{4}$ for 3 days. Primers specific to CAD1 or to actin genes were used.

ent role in the detoxification of $\mathrm{Zn}, \mathrm{Ni}$, and selenite ions. Differences between the two organisms were observed with respect to $\mathrm{Cu}, \mathrm{Hg}$, and $\mathrm{Ag}$.

PC synthesis is activated both in vivo and in vitro by some metal ions to which the corresponding PC synthase mutant is not hypersensitive. For example, both the expressed Arabidopsis enzyme in vitro and PC synthesis in vivo (P.B. Goldsbrough, unpublished data) are efficiently activated by $\mathrm{Cu}$. However, the cad1-3 mutant is only slightly more sensitive to $\mathrm{Cu}$ than is the wild type. Similarly, $\mathrm{Zn}$ activates both the expressed S. pombe enzyme in vitro and $P C$ synthesis in S. pombe in vivo (Grill et al., 1986), but the PC synthasedeficient mutant is not more sensitive to $\mathrm{Zn}$ than is the wild type. Although PC synthesis may be activated in vivo by particular metal ions, PCs may play little or no role in their detoxification. This may be due, for example, to inefficient sequestration to the vacuole and an inability to form stable complexes or to the operation of other more effective mechanisms for the detoxification of these metals. Together, these observations indicate that in vitro data on the relative efficiency of activation of PC synthase by various heavy metal ions should not be regarded as reflecting the role of $P C s$ in the detoxification of those metal ions in vivo.

The alignment of the polypeptide sequences derived from the plant, yeast, and nematode genes leads to speculation about the function of the conserved and variable regions of the $\mathrm{PC}$ synthase enzymes. The conserved $\mathrm{N}$-terminal domain must possess PC synthase catalytic activity. The protein encoded by the cad1- 5 allele is predicted to terminate at position 280 and lacks almost two-fifths of the wild-type protein. However, this mutant is the least sensitive to $\mathrm{Cd}$. Although no PC synthase activity was detected in extracts of this mutant, it accumulated $33 \%$ of the wild-type levels of PCs in vivo, indicating that the mutant gene product retains some activity (Howden et al., 1995a). Because a truncation of part of a catalytic function is likely to completely abolish activity, this observation supports the hypothesis that the $\mathrm{C}$-terminal domain is not absolutely required for catalytic function. 
The mechanism by which PC synthase is activated by a wide range of heavy metals and the basis of variations in the specificity and efficiency of activation of enzymes from different organisms are of particular interest. Activation probably arises from metal ions interacting with residues in the conserved, presumably catalytic, domain. Many heavy metal binding motifs contain Cys and His residues. Five $\mathrm{Cys}$ residues (two of which are adjacent) and a single $\mathrm{H}$ is residue are conserved across the three sequences and may play a role in activation of the enzyme. In addition, there is likely to be a role in enzyme activation for the multiple $C y s$ residues in the variable $\mathrm{C}$-terminal region. One hypothesis is that the $\mathrm{Cys}$ residues of the $\mathrm{C}$-terminal region provide a local sensor by binding heavy metal ions and bringing them into contact with the activation site in the catalytic domain of the protein. Thus, there may be few constraints on the primary amino acid sequence of this region other than the requirement for multiple $C y s$ residues.

No PCs were detected in the cad1-3 mutant after prolonged exposure to $\mathrm{Cd}$. This appears to indicate that only a single active PC synthase gene occurs in the Columbia ecotype. However, there is a second predicted gene on chromosome 1 with considerable similarity to CAD1. One possible explanation is that this gene encodes a functional PC synthase that is activated by other metal ions but not by $C d$. To test this hypothesis, we assayed cad1-3 seedlings exposed to $\mathrm{Zn}, \mathrm{Ni}, \mathrm{Pb}, \mathrm{SeO}_{3}, \mathrm{Ag}$, and $\mathrm{Hg}$ ions for $\mathrm{PC}$ accumulation. In no case were $P C s$ detected (data not shown). In view of the lack of specificity of activation of PC synthase by metal ions, it seems unlikely that a functional PC synthase homolog would not be activated by at least some of the metals tested. An alternative hypothesis is that the homologous gene is nonfunctional at some level. However, there are no obvious mutations that would render the gene nonfunctional, such as deletions of highly conserved regions, frameshift mutations, or splice-site mutations. It is not known whether the gene is transcribed. Further analysis of this gene is required to determine whether it is functional.

The identification of a similar gene in $C$. elegans is of considerable interest because PCs have not been detected in any animal species. Currently, we have no evidence that this gene also encodes a protein with PC synthase activity. However, in view of the high level of identity of the nematode gene product with the conserved $\mathrm{N}$-terminal domains of the yeast and plant enzymes as well as the presence of a variable domain containing multiple Cys residues, it seems likely that it too encodes PC synthase. Preliminary HPLC assays of extracts of $C$. elegans have identified a $C d$-inducible peak corresponding to $\mathrm{PC}_{(\mathrm{n}=2)}$ (A.P. Smith and P.B. Goldsbrough, unpublished data). However, the structure of this compound must be confirmed. In addition, by using PCR, sequences similar to the conserved regions of the three genes have been identified from both the aquatic midge, Chironomus, and earthworm species (W.M. Dietrich and C.S. Cobbett, unpublished data).

Originally, in the absence of evidence for class I or II metal- lothioneins in plants, PCs were regarded as the functional equivalent of animal metallothioneins (Grill et al., 1987). Subsequently, with the identification of metallothionein-like genes (Robinson et. al., 1993; Zhou and Goldsbrough, 1994) and metallothioneins (Murphy et al., 1997) in plants, it seemed more likely that the two classes of metal binding ligands played different or possibly overlapping roles in metal detoxification or metabolism. Nonetheless, the absence of reports of PCs in animals suggested a phylogenetic divergence between the animal and other kingdoms in the requirement for the two classes of ligand. Together, these observations suggest that this apparent divergence may not be real and that PCs may play a role in heavy metal detoxification in more types of organisms than were previously expected. A more thorough exploration of the spectrum of species containing similar genes will be of interest.

In conclusion, the identification of PC synthase genes in both yeast and plant species, and possibly in animal species as well, will stimulate further studies on the mechanism and regulation of $\mathrm{PC}$ biosynthesis. $\mathrm{PC}$ synthase is unrelated in sequence, and presumably in structure, to other proteins and thus may identify a new mechanism by which an enzyme may be activated in a relatively nonspecific manner by heavy metal ions. The manipulation of PC synthase expression in transgenic plants may also enhance the capacity of plants to be effective in the phytoremediation of heavy metal-contaminated environments.

\section{METHODS}

\section{Plant Strains and Growth Conditions}

Arabidopsis thaliana plants were grown as previously described (Howden and Cobbett, 1992). The cadl mutants have been described previously (Howden et al., 1995a). To measure the sensitivity of the cad1-3 mutant compared with the wild type, we transferred 7-day-old seedlings to $25 \mathrm{~mL}$ of agar medium containing added heavy metal. Each Petri dish contained 10 mutant and 10 wild-type seedlings. The plates were sealed with gas-permeable tape and incubated for an additional 10 days, when the shoot portions of the plants were weighed.

\section{Mapping CAD1}

Restriction fragment length polymorphism (RFLP) mapping of CAD1 was conducted essentially as described by Cobbett et al. (1998) for the CAD2 locus. Markers were m423 (Chang et al., 1988), pAt5-91.5 (Shirley et al., 1992), and sAt2105 (Pang et al., 1988). Further recombinants were obtained as follows. The GLABROUS3 (GL3), TRANSPARENT TESTA3 (TT3), and CAD1 loci are linked on chromosome 5 of Arabidopsis. From a cross between strain M24 (gl3 tz cer3 er) (Landsberg erecta ecotype) and the cad1-1 mutant (Columbia ecotype), a gl3-3 cad1-1 double mutant line was generated in which both the TT3 and cad1-1 loci were derived from the Columbia parent. Eighty-nine recombinants between the GL3 and CAD1 loci were 
identified phenotypically from a cross between the gl3 cad1-1 line and the Landsberg erecta ecotype. These were further analyzed for recombination in the TT3-CAD1 interval by using an EcoRI RFLP between the two ecotypes detected by clone pAt5-91.2. Markers used to further map CAD1 were CIC5F12LE and CIC15C8RE, both of which detected ECORV RFLPs on DNA gel blots, and polymerase chain reaction (PCR)-amplified polymorphic markers corresponding to the following regions of MRH10: MRH10.7 (primers 5'-CGGAGAAGAGTAATGTCGTAGA-3' and 5'-GTCCATAAAATAGGTAGGTAGC-3'; Sacl polymorphism), MRH10.9 (primers 5'-ACAAACGCCACAAAGGTAGATT-3' and 5'-GAAGGATAGACCAAAGAACAAC-3'; HindIII polymorphism), MRH10.10 (primers 5'-TGGGACTAAATAATCGGACTCG-3' and 5'-AACCTTCACTTTCTTGCGTCTG-3'; PCR product only from Columbia ecotype), MRH10(56-61) (primers 5'CAGACGCAAGAAAGTGAAGGTT-3' and 5'-AGAGGAGGAGAAATGAAAGGAC-3'; PCR product size polymorphism), and MRH10(61-65) (primers 5'-GTCCTTTCATTTCTCCTCCTCT-3' and 5'-GGATGACTAAAGGATTGACGAC-3'; BamHI polymorphism).

Each cad 1 mutant allele was amplified by PCR using primers with the following sequences: 5'-AGCGAAACAAGAAAACACTAAT-3' and 5'-ATTTGTGGATAGTGGATTCATA-3'. Nucleotide sequences were determined directly from two independently amplified templates.

\section{Complementation of the cad1-3 Mutant}

An 8.4-kb Xhol-Sacl fragment spanning the MRH10.11 gene was ligated into pBI101.3 (Clontech, Palo Alto, CA) and transformed into Agrobacterium tumefaciens GV3101/pM P 90 by electroporation. This construct and the parent plasmid pBI101.3 were transformed into cad1-3 plants by vacuum infiltration (Bechtold et al., 1993). Transformant seedlings were selected in the presence of $50 \mu \mathrm{g} / \mathrm{mL}$ kanamycin.

\section{Construction and Analysis of the Schizosaccharomyces pombe Mutant}

A 4.5-kb fragment spanning the S. pombe PC synthase gene was ligated into pBluescript SK + (Stratagene, La J olla, CA). The Smal-Pstl fragment spanning codons 107 to 277 was deleted and replaced with the ura $4^{+}$marker as a Hincll-Pstl fragment. The resulting fragment was transformed into S. pombe of genotype ura4-D18 leu1-32 ade6$704 \mathrm{~h}$, and transformants were selected by uracil prototrophy. Transformants were replica-plated to minimal medium containing $500 \mu \mathrm{M}$ $\mathrm{CdSO}_{4}$, and $\sim 50 \%$ were $\mathrm{Cd}$ sensitive. Successful targeting of the phytochelatin $(\mathrm{PC})$ synthase gene in these strains was confirmed by $P C R$. Methods for propagation and manipulation of S. pombe were as described by Moreno et al. (1991). Exponentially growing cells were exposed to $50 \mathrm{mM} \mathrm{CdCl}$ for $24 \mathrm{hr}$, centrifuged, resuspended in $50 \mathrm{mM}$ Tris- $\mathrm{HCl}, \mathrm{pH} 7.9,14 \%$ (v/v) glycerol, and $10 \mathrm{mM} \beta$-mercaptoethanol, and disrupted by vortexing with glass beads. After removal of cell debris by centrifugation, an aliquot of supernatant was mixed with an equal volume of $10 \%$ sulfosalicylic acid, precipitated protein was removed by centrifugation, and the supernatant was analyzed for PCs by HPLC, as described previously (Howden et al., 1995a).

\section{Expression of PC Synthase Genes in Escherichia coli}

The CAD1 CDNA was amplified by PCR using primers that introduced BstHI and Sacl sites at the putative initiation codon and downstream, respectively, of the open reading frame. Similarly, Ncol and $\mathrm{Sacl}$ sites flanking the $\mathrm{S}$. pombe gene were introduced by amplification from genomic DNA. The resulting fragments were digested and ligated between the $\mathrm{Ncol}$ and Sacl sites of pTrc99A (Pharmacia) and confirmed by nucleotide sequencing. The expression constructs were transformed into $\mathrm{E}$. coli strain $\mathrm{DH} 5 \alpha$. Cells were grown to an $\mathrm{OD}_{600}$ of $\sim 0.6$, treated with $100 \mu \mathrm{M}$ isopropyl- $\beta$-D isothiogalactopyranoside, and grown for an additional $3 \mathrm{hr}$. An extract was prepared by sonicating the collected bacteria in buffer $(50 \mathrm{mM}$ Tris- $\mathrm{HCl}, \mathrm{pH}$ $7.9,14 \%$ [v/v] glycerol, and $10 \mathrm{mM} \beta$-mercaptoethanol). The supernatant was assayed for PC synthase activity, as described previously (Chen et al., 1997), except that the reaction time was 15 min.

\section{Reverse Transcription-PCR Analysis of Gene Expression}

Ten-day-old Arabidopsis plants were grown in agar medium and transferred to medium containing $1.5 \mu \mathrm{M} \mathrm{CdSO}_{4}$; root and leaf tissues were harvested separately after another 3 days. Total RNA was isolated using the RNeasy Mini kit (Qiagen, Chatsworth, CA), according to the manufacturer's instructions. CDNA was synthesized from $5 \mu \mathrm{g}$ of total RNA using the SuperS cript kit (Life Technologies, Gaithersburg, MD), according to the manufacturer's instructions. Independent PCR reactions using equal aliquots of CDNA samples were performed using CAD1-specific primers ( $5^{\prime}$-CTCGTTTCAAGTATCCCCCTCAC-3' and 5'-GCTTCAGGACCACATTCACACTC-3') or aCtin gene-specific primers (5'-GGTAACATTGTGCTCAGTGGTGG-3' and $5^{\prime}$-CTCGGCCTTGGAGATCCACATC-3'). Reactions contained

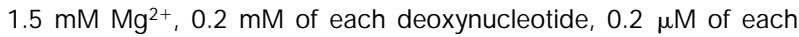
primer, and 0.28 units of Taq polymerase. Primers were annealed at $65^{\circ} \mathrm{C}$ for $30 \mathrm{sec}$, and DNA was synthesized at $68^{\circ} \mathrm{C}$ for 3 min for 35 cycles. Preliminary experiments demonstrated that the amount of PCR product increased with increasing numbers of cycles, indicating that the reaction components were not limiting.

\section{ACKNOWLEDGMENTS}

We thank Bernie Leinberger for excellent technical assistance; Murali Dhandaydham, Brenda Shirley, Elliot Meyerowitz, and Alan Coulson for clones; and the Nottingham Arabidopsis Stock Center (Nottingham, UK) and the Arabidopsis Biological Resource Center (Columbus, $\mathrm{OH})$ for seeds and libraries. C.S.C. and P.B.G. are supported by grants from the Australian Research Council and the U.S. Department of Agriculture National Research Initiative Competitive Grants Program, respectively.

Received February 1, 1999; accepted March 26, 1999.

\section{REFERENCES}

Bechtold, N., Ellis, J ., and Pelletier, G. (1993). In planta Agrobacterium mediated gene transfer by infiltration of adult Arabidopsis plants. C. R. Acad. Sci. Paris Sci. Vie 316, 1194-1199.

Chang, C., Bowman, J.L., DeJ ohn, A.W., Lander, E.S., and 
Meyerowitz, E.M. (1988). Restriction fragment length polymorphism linkage map for Arabidopsis thaliana. Proc. Natl. Acad. Sci. USA 85, 6856-6859.

Chen, J ., Zhou, J ., and Goldsbrough, P.B. (1997). Characterization of phytochelatin synthase from tomato. Physiol. Plant. 101, 165-172.

Cobbett, C.S., May, M.J ., Howden, R., and Rolls, B. (1998). The glutathione-deficient, cadmium-sensitive mutant, cad2-1, of Arabidopsis thaliana is deficient in $\gamma$-glutamylcysteine synthetase. Plant J . 16, 73-78.

Dameron, C.T., Reese, R.N., Mehra, R.K., Kortan, A.R., Carroll, P.J ., Steigerwald, M.L., Brus, L.E., and Winge, D.R. (1989). B iosynthesis of cadmium sulfide quantum semiconductor crystallites. Nature 338, 596-597.

Gekeler, W., Grill, E., Winnacker, E.-L., and Zenk, M.H. (1989). Survey of the plant kingdom for the ability to bind heavy metals through phytochelatins. Z. Naturforsch. Sect C Biosci. 44, 361-369.

Glaeser, H., Coblenz, A., Kruczek, R., Ruttke, l., Ebert-J ung, A., and Wolf, K. (1991). Glutathione metabolism and heavy metal detoxification in Schizosaccharomyces pombe. Curr. Genet. 19, 207-213.

Grill, E., Winnacker, E.L., and Zenk, M.H. (1986). Synthesis of seven different homologous phytochelatins in metal-exposed Schizosaccharomyces pombe cells. FEBS Lett. 197, 115-120.

Grill, E., Winnacker, E.L., and Zenk, M.H. (1987). Phytochelatins, a class of heavy-metal-binding peptides from plants are functionally analogous to metallothioneins. Proc. Natl. Acad. Sci. USA 84, 439-443.

Grill, E., Thumann, J., Winnacker, E.L., and Zenk, M.H. (1988). Induction of heavy-metal binding phytochelatins by innoculation of cell cultures in standard media. Plant Cell Rep. 7, 375-378.

Grill, E., Loeffler, S., Winnacker, E.L., and Zenk, M.H. (1989). Phytochelatins, the heavy-metal-binding peptides of plants, are synthesized from glutathione by a specific $\gamma$-glutamylcysteine dipeptidyl transpeptidase (phytochelatin synthase). Proc. Natl. Acad. Sci. USA 86, 6838-6842.

Hayashi, Y., Nakagawa, C.W., Mutoh, N., Isobe, M., and Goto, T. (1991). Two pathways in the biosynthesis of cadystins $(\gamma-E C)_{n} G$ in the cell-free system of the fission yeast. Biochem. Cell. Biol. 69, 115-121.

Howden, R., and Cobbett, C.S. (1992). Cadmium-sensitive mutants of Arabidopsis thaliana. Plant Physiol. 100, 100-107.

Howden, R., Goldsbrough, P.B., Andersen, C.R., and Cobbett, C.S. (1995a). Cadmium-sensitive cadl mutants of Arabidopsis thaliana are phytochelatin deficient. Plant Physiol. 107, 1059-1066.

Howden, R., Andersen, C.R., Goldsbrough, P.B., and Cobbett, C.S. (1995b). A cadmium-sensitive, glutathione-deficient mutant of Arabidopsis thaliana. Plant Physiol. 107, 1067-1073.

J uang, R.-H., McCue, K.F., and Ow, D.W. (1993). Two purine biosynthetic enzymes that are required for cadmium tolerance in Schizosaccharomyces pombe utilize cysteine sulfinate in vitro. Arch. Biochem. Biophys. 304, 392-401.

Kägi, J .H.R. (1991). Overview of metallothionein. Methods Enzymol. 205, 613-626
Klapheck, S., Schlunz, S., and Bergmann, L. (1995). Synthesis of phytochelatins and homo-phytochelatins in Pisum sativum L. Plant Physiol. 107, 515-521.

Kneer, R., and Zenk, M.H. (1992). Phytochelatins protect plant enzymes from heavy metal poisoning. Phytochemistry 31, 26632667

Kneer, R., Kutchan, T.M., Hochberger, A., and Zenk, M.H. (1992) Saccharomyces cerevisiae and Neurospora crassa contain heavy metal sequestering phytochelatin. Arch. Microbiol. 157, 305-310.

Loeffler, S., Hochberger, A., Grill, E., Winnacker, E.L., and Zenk, M.H. (1989). Termination of the phytochelatin synthase reaction through sequestration of heavy metals by the reaction product. FEBS Lett. 258, 42-46.

Maitani, T., Kubota, H., Sato, K., and Yamada, T. (1996). The composition of metals bound to class III metallothionein (phytochelatin and its desglycyl peptide) induced by various metals in root cultures of Rubia tinctorum. Plant Physiol. 110, 1145-1150.

Mehra, R.K., Tarbet, E.B., Gray, W.R., and Winge, D.R. (1988). Metal-specific synthesis of two metallothioneins and $\gamma$-glutamyl peptides in Candida glabrata. Proc. Natl. Acad. Sci. USA 85, 8815-8819.

Mehra, R.K., Mulchandani, P., and Hunter, T.C. (1994). Role of CdS quantum crystallites in cadmium resistance in Candida glabrata. Biochem. Biophys. Res. Commun. 200, 1193-1200.

Morelli, E., and Pratesi, E. (1997). Production of phytochelatins in the marine diatom Phaeodactylum tricornutum in response to copper and cadmium exposure. Bull. Environ. Contam. Toxicol. $\mathbf{5 9}, 657-664$

Moreno, S., Klar, A., and Nurse, P. (1991). Molecular genetic analysis of fission yeast Schizosaccharomyces pombe. Methods Enzymol. 194, 795-823.

Murphy, A., Zhou, J ., Goldsbrough, P.B., and Taiz, L. (1997). Purification and immunological identification of metallothioneins 1 and 2 from Arabidopsis thaliana. Plant Physiol. 113, 1293-1301.

Mutoh, N., and Hayashi, Y. (1988). Isolation of mutants of Schizosaccharomyces pombe unable to synthesize cadystins, small cadmium-binding peptides. Biochem. Biophys. Res. Commun. 151, 32-39.

Ortiz, D.F., Kreppel, L., Speiser, D.M., Scheel, G., McDonald, G., and Ow, D.W. (1992). Heavy-metal tolerance in the fission yeast requires an ATP-binding cassette-type vacuolar membrane transporter. EMBO J . 11, 3491-3499.

Ortiz, D.F., Ruscitti, T., McCue, K.F., and Ow, D.W. (1995). Transport of metal-binding peptides by HMT1, a fission yeast ABC-type vacuolar membrane protein. J. Biol. Chem. 270, 4721-4728.

Pang, P.P., Pruit, R.E., and Meyerowitz, E.M. (1988). Molecular cloning, genomic organization, expression and evolution of $12 \mathrm{~S}$ seed storage protein genes of Arabidopsis thaliana. Plant. Mol. Biol. 11, 805-820.

Reese, R.N., and Wagner, G.J . (1987). Effects of buthionine sulfoximine on $\mathrm{Cd}$-binding peptide levels in suspension-cultured tobacco cells treated with $\mathrm{Cd}, \mathrm{Zn}$, or Cu. Plant Physiol. 84, 574-577.

Reese, R.N., and Winge, D.R. (1988). Sulfide stabilization of the 
cadmium- $\gamma$-glutamyl peptide complex of Schizosaccharomyces pombe. J . Biol. Chem. 263, 12832-12835.

Reese, R.N., White, C.A., and Winge, D.R. (1992). Cadmium sulfide crystallites in $C d-(\gamma-E C)_{n} G$ peptide complexes from tomato. Plant Physiol. 98, 225-229.

Robinson, N.J ., Tommey, A.M., Kuske, C., and Jackson, P.J . (1993). Plant metallothioneins. Biochem. J . 295, 1-10.

Scheller, H.B., Huang, B., Hatch, E., and Goldsbrough, P.B. (1987). Phytochelatin synthesis and glutathione levels in response to heavy metals in tomato cells. Plant Physiol. 85, 1031-1035.

Shirley, B.W., Hanley, S., and Goodman, H.M. (1992). Effects of ionizing radiation on a plant genome: Analysis of two Arabidopsis transparent testa mutations. Plant Cell 4, 333-347.

Speiser, D.M., Abrahamson, S.L., Banuelos, G., and Ow, D.W. (1992a). Brassica juncea produces a phytochelatin-cadmium-sulfide complex. Plant Physiol. 99, 817-821.

Speiser, D.M., Ortiz, D.F., Kreppel, L., and Ow, D.W. (1992b). Purine biosynthetic genes are required for cadmium tolerance in Schizosaccharomyces pombe. Mol. Cell. Biol. 12, 5301-5310.
Steffens, J .C., Hunt, D.F., and Williams, B.G. (1986). Accumulation of non-protein metal-binding polypeptides ( $\gamma$-glutamyl-cysteinyl $)_{n-}$ glycine in selected cadmium-resistant tomato cells. J . Biol. Chem. 261, 13879-13882.

Zhou, J ., and Goldsbrough, P.B. (1994). Functional homologs of fungal metallothionein genes from Arabidopsis. Plant Cell 6, 875-884.

\section{NOTE ADDED IN PROOF}

The authors have recently become aware of two other papers (Vatamaniuk, O.K., Mari, S., Lu, Y.-P., and Rea, P.A. [1999]. AtPCS1, a phytochelatin synthase from Arabidopsis: Isolation and in vitro reconstitution. Proc. Natl. Acad. Sci. USA. 96, in press; Clemens, S., Kim, E.J ., Neumann, D., and Schroeder, J .I. [1999]. Tolerance to toxic metals by a gene family of phytochelatin synthases from plants and yeast. EMBO J . 18, in press.) describing the identification of phytochelatin synthase genes in plants and yeast. 